\title{
The alveolar epithelial cells are involved in pulmonary vascular remodeling and constriction of hypoxic pulmonary hypertension
}

Yanxia Wang ${ }^{1 \dagger}$, Xiaoming $\mathrm{Li}^{5 \dagger}$, Wen $\mathrm{Niu}^{2 \dagger}$, Jian $\mathrm{Chen}^{4 \dagger}$, Bo Zhang ${ }^{2}$, Xiumin Zhang ${ }^{1}$, Yingmei Wang ${ }^{1}$, Shaokang Dang ${ }^{4^{*}}$ and Zhichao $\mathrm{Li}^{2,3^{*}}$

\begin{abstract}
Background: Hypoxic pulmonary hypertension $(\mathrm{HPH})$ is a common type of pulmonary hypertension and characterized by pulmonary vascular remodeling and constriction. Alveolar epithelial cells (AECs) primarily sense alveolar hypoxia, but the role of AECs in HPH remains unclear. In this study, we explored whether AECs are involved in pulmonary vascular remodeling and constriction.
\end{abstract}

Methods: In the constructed rat HPH model, hemodynamic and morphological characteristics were measured. By treating AECs with hypoxia, we further detected the levels of superoxide dismutase 2 (SOD2), catalase (CAT), reactive oxygen species (ROS) and hydrogen peroxide $\left(\mathrm{H}_{2} \mathrm{O}_{2}\right)$, respectively. To detect the effects of AECs on pulmonary vascular remodeling and constriction, AECs and pulmonary artery smooth cells (PASMCs) were co-cultured under hypoxia, and PASMCs and isolated pulmonary artery (PA) were treated with AECs hypoxic culture medium. In addition, to explore the mechanism of AECs on pulmonary vascular remodeling and constriction, $\mathrm{ROS}$ inhibitor $\mathrm{N}$-acetylcysteine (NAC) was used.

Results: Hypoxia caused pulmonary vascular remodeling and increased pulmonary artery pressure, but had little effect on non-pulmonary vessels in vivo. Meanwhile, in vitro, hypoxia promoted the imbalance of SOD2 and CAT in AECs, leading to increased $\mathrm{ROS}$ and hydrogen peroxide $\left(\mathrm{H}_{2} \mathrm{O}_{2}\right)$ production in the AECs culture medium. In addition, AECs caused the proliferation of co-cultured PASMCs under hypoxia, and the hypoxic culture medium of AECs enhanced the constriction of isolated PA. However, treatment with ROS inhibitor NAC effectively alleviated the above effects.

Conclusion: The findings of present study demonstrated that AECs were involved in pulmonary vascular remodeling and constriction under hypoxia by paracrine $\mathrm{H}_{2} \mathrm{O}_{2}$ into the pulmonary vascular microenvironment.

\footnotetext{
*Correspondence: 994740545@qq.com; lizhic@fmmu.edu.cn

†Yanxia Wang, Xiaoming Li, Wen Niu, and Jian Chen contributed equally to this work

${ }^{2}$ Department of Pathophysiology, School of Basic Medicine, Fourth Military Medical University, 169 Changle Western Street, Xi'an, Shaanxi 710032, People's Republic of China

${ }^{4}$ Department of Respiratory and Critical Care, Tangdu Hospital, Fourth Military Medical University, 569 Xinsi Street, Xi'an, Shaanxi 710038, People's Republic of China

Full list of author information is available at the end of the article
}

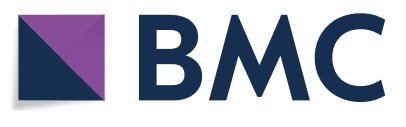

(c) The Author(s) 2021. Open Access This article is licensed under a Creative Commons Attribution 4.0 International License, which permits use, sharing, adaptation, distribution and reproduction in any medium or format, as long as you give appropriate credit to the original author(s) and the source, provide a link to the Creative Commons licence, and indicate if changes were made. The images or other third party material in this article are included in the article's Creative Commons licence, unless indicated otherwise in a credit line to the material. If material is not included in the article's Creative Commons licence and your intended use is not permitted by statutory regulation or exceeds the permitted use, you will need to obtain permission directly from the copyright holder. To view a copy of this licence, visit http://creativecommons.org/licenses/by/4.0/. The Creative Commons Public Domain Dedication waiver (http://creativeco mmons.org/publicdomain/zero/1.0/) applies to the data made available in this article, unless otherwise stated in a credit line to the data. 
Keywords: Alveolar epithelial cells, Hypoxic pulmonary hypertension, Pulmonary vascular remodeling and constriction, Reactive oxygen species

\section{Background}

Pulmonary hypertension is a progressive disorder and characterized by pulmonary vascular remodeling and vasoconstriction [1-3], which ultimately leads to right ventricular hypertrophy and right heart failure, as well as morbidity and mortality [4-6]. Hypoxic pulmonary hypertension ( $\mathrm{HPH})$ is highly prevalent in advanced chronic obstructive pulmonary disease and high altitude hypoxia [7], and has a complex pathological process involving multiple mechanisms. Although there are many studies on the mechanism of $\mathrm{HPH}$, the underlying molecular mechanisms are not yet fully elucidated to this date. Therefore, it is highly needed to further explore novel mechanism of $\mathrm{HPH}$.

It is well known that the pulmonary vascular system responds to hypoxia with vasoconstriction rather than vasodilation like in the systemic circulation [8]. Alveolar hypoxia causes the increase of pulmonary artery pressure, but there is no systemic circulation pressure increase. Alveolar hypoxia is primarily sensed at the alveolo capillary membrane, which is formed by juxtaposed epithelial and endothelial membranes in the alveolar wall, from where the hypoxic signal is propagated to pulmonary arterioles and subsequently triggers constriction of pulmonary artery smooth cells (PASMCs) [9]. In the lung, although alveolar epithelial cells (AECs) and endothelial cells were responsive to altered oxygen tensions, AECs were generally more sensitive than endothelial cells in regulation of hypoxic adaptation [10]. In the alveolar wall, the tight junction of epithelium and endothelium strongly indicates the presence of direct crosstalk [9]. Recently, the key role of endothelial cell-SMC crosstalk on HPH has been proposed [8, 11-15]. However, it is almost unknown whether AECs are involved in the development of HPH. The aim of the study was to analyze the role and possible mechanisms by which AECs are involved in HPH.

The electron transfer process produces reactive oxygen species (ROS) such as hydroxide radicals ( $\left.\mathrm{HO}^{*}\right)$, singlet oxygen $\left({ }^{1} \mathrm{O} 2\right)$, superoxide anions $\left(\mathrm{O}_{2}{ }^{-}\right)$and hydrogen peroxide $\left(\mathrm{H}_{2} \mathrm{O}_{2}\right)$ [16-18]. In the cell normal metabolism, the antioxidant enzymes superoxide dismutase (SOD), catalase (CAT) and peroxidase (POD) can prevent the accumulation of $\mathrm{O}_{2}-$ and $\mathrm{H}_{2} \mathrm{O}_{2}[19,20]$. The balance between production and degradation rates determines the steady-state concentrations of ROS in each intracellular compartment. $\mathrm{H}_{2} \mathrm{O}_{2}$ is a stable and easily diffused out of the cell [18]. $\mathrm{H}_{2} \mathrm{O}_{2}$ has been shown to be involved in cell proliferation [21], cell-cycle arrest [22] and apoptosis [23] and vascular smooth muscle constriction [24]. The multiple responses of the lung to oxygen are a physiological paradigm of the variety of cellular responses to ROS in vitro. In the alveolus, AECs are the first to sense changes of oxygen concentration. Recently, there is evidence that hypoxia leads to a significant increase in the concentration of ROS in AECs $[15,25]$. A recent study has shown that cell proliferation can be achieved only by exposing cells to a constant flow of $\mathrm{H}_{2} \mathrm{O}_{2}$ generated by the the glucose/glucose oxidase (G/GO) system [26]. Therefore, AECs, as the cells around the pulmonary capillaries, can affect the pulmonary vascular remodeling and constriction by constant release of $\mathrm{H}_{2} \mathrm{O}_{2}$.

In this study, we reported that AECs were involved in pulmonary vascular remodeling and constriction by paracrine $\mathrm{H}_{2} \mathrm{O}_{2}$ to pulmonary vascular microenvironment. And the upregulation of $\mathrm{H}_{2} \mathrm{O}_{2}$ in AECs was caused by imbalance of SOD2 and CAT under hypoxia. We hypothesized that the up-regulation of $\mathrm{H}_{2} \mathrm{O}_{2}$ in AECs could provide a novel mechanism into the pathogenesis of $\mathrm{HPH}$.

\section{Methods \\ Experimental protocol}

Male Sprague-Dawley rats (200-250 g) were purchased from the animal center of the Fourth Military Medical University (Xi'an, China). All animal experimental procedures were approved by Animal Care and Use Committee of the Fourth Military Medical University and complied with the Declaration of the National Institutes of Health Guide for Care and Use of Laboratory Animals (certificate No. 201000082, Grade II). To obtain pulmonary hypertension rats, rats were housed intermittently in a hypobaric hypoxia chamber depressurized to $380 \mathrm{mmHg}$ (10\% oxygen) and subjected to hypobaric hypoxia challenge of $8 \mathrm{~h} / \mathrm{d}$ for 4 weeks. Age-matched rats were housed in room air (21\% oxygen) accordingly as controls.

Hemodynamic and histological analysis: the measurement of right ventricular pressure and the hematoxylin and eosin staining of lung and renal tissues were performed according to our established protocol [27]. Briefly, after 4 weeks of hypoxia, the animals were anesthetized with $20 \%$ ethylurethan $(4 \mathrm{ml} / \mathrm{kg}$, i.p.). Then, a soft silica gel catheter linked to a Power lab system (AD Instruments, Colorado Springs, CO, Australia) was inserted into the right jugular vein. The right ventricle peak systolic pressure (RVSP) waveforms were showed on the monitor when the catheter arrived in the right ventricle 
chamber. Meanwhile, the mean carotid artery pressure (mCAP) was recorded via a special catheter inserted into the carotid artery. After the weight of right ventricle (RV) and left ventricle plus septum $(\mathrm{LV}+\mathrm{S})$ were obtained, the ratio of $\mathrm{RV} /(\mathrm{LV}+\mathrm{S})$ was calculated as an index of RV hypertrophy. The right lung and kidney were placed in neutral buffer ( $\mathrm{pH}$ 7.4) containing 10\% formalin for $72 \mathrm{~h}$ embedded in paraffin, sectioned into $5 \mu$ m thick sections and then subjected to hematoxylin and eosin staining. Microscopic evaluation showed structure remodeling of the pulmonary vessel. Total 60 of pulmonary vessel, bronchial vessel and renal vessel in approximate round shape were obtained from each group. Their external diameters are $50-180 \mu \mathrm{m}$ and the average size of artery was $78 \mu \mathrm{m}$. The outside diameter and inside diameter of pulmonary vessel were measured by an image-processing program (Image-Pro Plus, Version 5.1, Media Cybernetics, Rockville, MD, USA). The medial wall thickness, the cross-sectional area of medial wall, and the total crosssectional vessel area were obtained. Pulmonary vascular structure remodeling was assessed by percent medial wall thickness (MT \%) and percent medial wall area (MA $\%)$ two indices: $\mathrm{MT} \%=100 \times(2 \times$ medial wall thickness $)$ / (vessel diameter), MA\% $=100 \times($ cross sectional medial wall area) / (total cross-sectional vessel area). All the morphological analysis was conducted via a double-blind method.

Arterial rings isolation: the PA and aortic artery (AA) were obtained according to published articles [25]. Briefly, normoxic and HPH rats were anesthetized with $20 \%$ ethylurethan $(4 \mathrm{ml} / \mathrm{kg}$, i.p.). Lung and heart were removed and immersed into ice-cold oxygenated KrebsHenseleit solution (in mM: $\mathrm{NaCl} 127, \mathrm{KCl} 4.7, \mathrm{NaHCO}_{3}$ 17, $\mathrm{MgSO}_{4} 1.17, \mathrm{KH}_{2} \mathrm{PO}_{4} 1.18, \mathrm{CaCl}_{2} 2.5$, D-glucose 5.5) after median sternotomy was performed. Under a dissecting microscope, the third-division (external diameter $<300 \mu \mathrm{m}$ ) PA and AA were isolated carefully, cleared of connective tissue and cut into 3-mm-length rings. Endothelium was removed by gently rubbing the lumen with swab in rings. The PA and AA rings were suspended respectively on stainless steel hook connected to force transducers (AD Instruments, Colorado Springs, CO) for isometric force recording in individual water jacketed organ chamber containing modified Krebs-Henseleit solutions parged continuously with $95 \% \mathrm{O}_{2}$ and $5 \% \mathrm{CO}_{2}$ at $37{ }^{\circ} \mathrm{C}$. Isometric force was recorded with a force-displacement transducer and a PowerLab eight-channel data acquisition system (AD Instruments, Colorado Springs, CO, USA) and then was analyzed by MacLab/400 and Chart software (version 5.5 from ADInstruments).The pulmonary and aortic artery ring were stretched to a predetermined optimal passive tension of $500 \mathrm{mg}$ and $1000 \mathrm{mg}$, respectively and stabilized for $60 \mathrm{~min}$ with three washouts at 20-min intervals. Then reproducibility of contractile responses to $1 \mu \mathrm{M}$ phenylephrine (>300 mg) was established. The rings were rinsed with Krebs-Henseleit solution and the tension returned to baseline. To test the effects of $\mathrm{H}_{2} \mathrm{O}_{2}$ on the constriction of $\mathrm{PA}$ and $\mathrm{AA}$, dose-response curve was obtained by cumulative addition of exogenous $\mathrm{H}_{2} \mathrm{O}_{2}\left(5 \times 10^{-6}\right.$ to $\left.10^{-3} \mathrm{M}\right)$ at 10-min interval on PA and AA rings. The $\mathrm{H}_{2} \mathrm{O}_{2}$ concentration of the largest contractile force of artery was selected and then treated with ROS inhibitor N-acetylcysteine (NAC) for $10 \mathrm{~min}$ to observe the change of contractile force. To further confirm that AECs participated in the constriction of PA and AA, pulmonary and aortic ring from normoxic and $\mathrm{HPH}$ rats were treated with AECs normoxic and hypoxic culture medium and NAC at 10-min intervals to observe the change of contractile force. The medium with $5 \%$ fetal bovine serum (FBS) was used as a negative control. The experiments involving $\mathrm{NAC}$ and $\mathrm{H}_{2} \mathrm{O}_{2}$ were performed in the dark. For the vasoconstriction experiment, $1 \mu \mathrm{mol} / \mathrm{L} \mathrm{PE}$ was used. Vascular ring contraction to maximum was labeled as $100 \%$, and the contraction data for each group was expressed as a percentage of the maximum contraction caused by $1 \mu \mathrm{M}$ PE.

\section{Cell culture}

Rat primary PASMCs and AASMCs were obtained by tissue explants culturing method according to our established protocol [22]. PA and AA were isolated from male Sprague-Dawley rats (200-250 g) and dissected into small pieces after the adventitial layers were removed. Then, they were placed in an overturned culture flask containing Dulbecco Eagle's minimum essential Medium (DMEM, HyClone, Logan, UT) with 15\% FBS, CellMax, Beijing, China) at $37{ }^{\circ} \mathrm{C}$ in $21 \%$ oxygen condition. The flask was carefully turned over after $4 \mathrm{~h}$. PASMCs and AASMCs crawled out from the tissue in about a week. Cells were used between passages 3 to 6 . Smooth muscle cell was identified by positive staining for smooth muscle a-actin (mouse monoclonal antibody, Sigma-Aldrich, St. Louis, MO, USA) at each passage.

Alveolar epithelial cells (AECs) in this study were rat primary ATII cells. Rat primary ATII cells were isolated from male SpragueDawley rats (180-200 g) as previously described [28]. Pooled cells from 2 rats were prepared as follows. Rats were injected intraperitoneally with $20 \%$ ethylurethan $(4 \mathrm{ml} / \mathrm{kg}$, i.p.) and intravenously $4000 \mathrm{U} / \mathrm{kg}$ heparin sodium. Then, rats were exsanguinated by cutting the abdominal aorta under the aseptic condition. Blood was replaced by solution II $(50 \mathrm{ml})$ (in mM: $140 \mathrm{NaCl}, 5 \mathrm{KCl}, 10$ Hepes, $2 \mathrm{CaCl}_{2}, 2.5 \mathrm{PBS}$ (pH 7.4), $1.3 \mathrm{MgSO}_{4}$ ) which was perfused via the PA. The lungs were removed from the thorax and lavaged and 

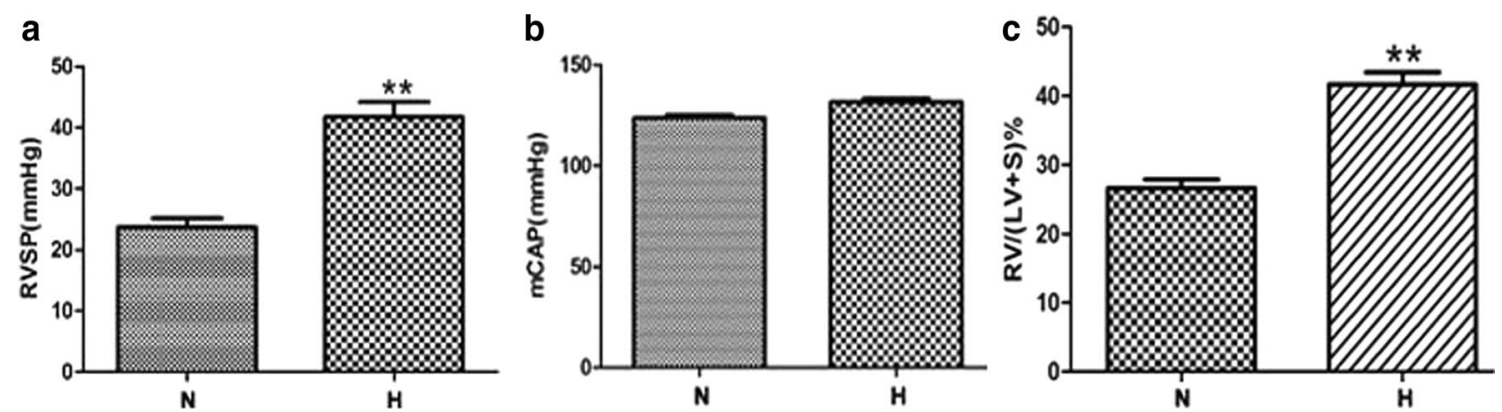

Fig. 1 Effects of hypoxia on RVSP, mCAP and right ventricular hypertrophy index in rats. a RVSP increased significantly in hypoxic group compared with the normoxic group. $\mathbf{b}$ Hypoxia had no significant effect on mCAP. $\mathbf{c}$ RV/(LV + S)\% increased significantly in hypoxic group compared with normoxic group. N: normoxic group, H: hypoxic group. $n=12$, Data are means \pm S.D. ${ }^{*} P<0.01$ vs. $N$

washed 8 times with the solution $\mathrm{I}(10 \mathrm{ml} /$ time) (in $\mathrm{mM}$ : $140 \mathrm{NaCl}, 5 \mathrm{KCl}, 10$ Hepes, 6 D-glucose, $2.5 \mathrm{PBS}$ (pH 7.4), 0.2 EDTA) and 2 times with the solution II (10 ml/time). Lungs were then filled 2 times with trypsin solution (10 $\mathrm{ml} /$ time) prepared in solution II and incubated in incubator for $10 \mathrm{~min}$ at $37^{\circ} \mathrm{C}$ every time. The lungs were dissected into small pieces in the presence of $4 \mathrm{ml}$ DNAse I and $5 \mathrm{ml} \mathrm{FBS}$. The lung tissues were then sequentially filtered through $125 \mu \mathrm{m}$ and $75 \mu \mathrm{m}$ stainless mesh. The filtrate was centrifuged at $1000 \mathrm{r} / \mathrm{min}$ for $8 \mathrm{~min}$. The cell pellet was resuspended in DMEM at $37^{\circ} \mathrm{C}$.The cell suspension was plated at a density of $2 \times 10^{6}$ cells $/ \mathrm{ml}$ in 25 $\mathrm{cm}^{2}$ bacteriologic plastic dishes coated rat IgG to remove macrophages and incubated at $37^{\circ} \mathrm{C}$ in $5 \% \mathrm{CO}_{2}$ incubator for $1 \mathrm{~h}$. The unattached cells in suspension were removed and centrifuged at $1000 \mathrm{r} / \mathrm{min}$ for $8 \mathrm{~min}$. The cell pellet was plated at a density of $5 \times 10^{5}$ cells $/ \mathrm{cm}^{2}$ in 6 -well culture plates with DMEM, 15\% FBS, $100 \mathrm{U} / \mathrm{ml}$ penicillin and $100 \mathrm{U} / \mathrm{ml}$ streptomycin and incubated at $37^{\circ} \mathrm{C}$ under $5 \% \mathrm{CO}_{2}$ incubator. The cell purity after $24 \mathrm{~h}$ was assessed by a characteristic fluorescence with phosphine3 Ras previously described [28]. AECs were seeded in 24-well culture plates at $5 \times 10^{3}$ cells per well under normoxic $(21 \%$ $\left.\mathrm{O}_{2}\right)$ or hypoxic conditions $\left(5 \% \mathrm{O}_{2}\right)$. AECs culture medium was collected at $24 \mathrm{~h}$ for the subsequent experiments.

\section{Cell treatment}

The effect of hypoxia on the proliferation of PASMCs and AASMCs was investigated under different oxygen concentrations. PASMCs and AASMCs were seeded in 96 -well culture plates at $3 \times 10^{4}$ cells per well under normoxic $\left(21 \% \mathrm{O}_{2}\right)$ or hypoxic conditions $\left(10 \% \mathrm{O}_{2}\right.$ and $5 \% \mathrm{O}_{2}$ ).

The effect of AECs on the proliferation of PASMCs and AASMCs was investigated using 24-well transwell insert co-culture model $(0.4 \mu \mathrm{m}$ pore). PASMCs and AASMCs were seeded in 24-well culture plates at a density of $3 \times 10^{4}$ cells per well, ATII were seeded in transwell inserts at a density of $1 \times 10^{4}$ cells per insert. The cells were maintained under normoxia $\left(21 \% \mathrm{O}_{2}\right)$ or hypoxia conditions $\left(5 \% \mathrm{O}_{2}\right)$. The cells were grouped as follows: (1) normoxia (2) hypoxia (3) co-culture with ATII under normoxia (4) co-culture with ATII under hypoxia.

To further confirm that AECs participated in the proliferation of PASMCs and AASMCs, the culture medium of PASMCs and AASMCs were replaced by AECs culture medium under normoxic or hypoxic conditions every $12 \mathrm{~h}$. The cells were grouped as follows: (1) normoxia (2) hypoxia (3) treatment with ATII normoxic culture medium under normoxia (4) treatment with ATII hypoxic culture medium under normoxia (5) treatment with ATII normoxic culture medium under hypoxia (6) treatment with ATII hypoxic culture medium under hypoxia.

We assessed the effects of $\mathrm{H}_{2} \mathrm{O}_{2}$ on the proliferation of PASMCs and AASMCs by the cumulative addition of exogenous $\mathrm{H}_{2} \mathrm{O}_{2}\left(5 \times 10^{-6}\right.$ to $\left.10^{-3} \mathrm{M}\right)$. The $\mathrm{H}_{2} \mathrm{O}_{2}$ concentration of the largest proliferation of PASMCs and AASMCs was selected and then treated with NAC (5 mMand $10 \mathrm{mM}$ ) to observe the change of proliferation. As well as NAC $(10 \mathrm{mM})$ was used in the co-culture system.

To better investigate the effects of hypoxia on cell proliferation, direct cell counting was performed. Cells were seeded $6 \times 10^{4}$ cells in 6 -well plates and cultured

(See figure on next page.)

Fig. 2 Effects of hypoxia on structure of pulmonary and systemic vessels in rats. A Reconstruction of pulmonary and systemic artery were observed by HE staining $(\mathbf{a}-\mathbf{c})$ pulmonary artery, bronchial artery and renal artery of normoxic group $(\mathbf{d}-\mathbf{f})$ pulmonary artery, bronchial artery and renal artery of hypoxic group. B MT\% and MA\% of pulmonary and bronchial artery were significantly increased in hypoxic group compared with the normoxic group $(\mathbf{a}, \mathbf{b})$ MT\% and MA\% of pulmonary artery $(\mathbf{c}, \mathbf{d})$ MT\% and MA\% of bronchial artery $(\mathbf{e}, \mathbf{f})$ MT\% and MA\% of renal artery. N: normoxic group, H: hypoxic group. $n=12$, Data are means \pm S.D. ${ }^{* *} \mathrm{P}<0.01$ vs. $\mathrm{N}$ 
A
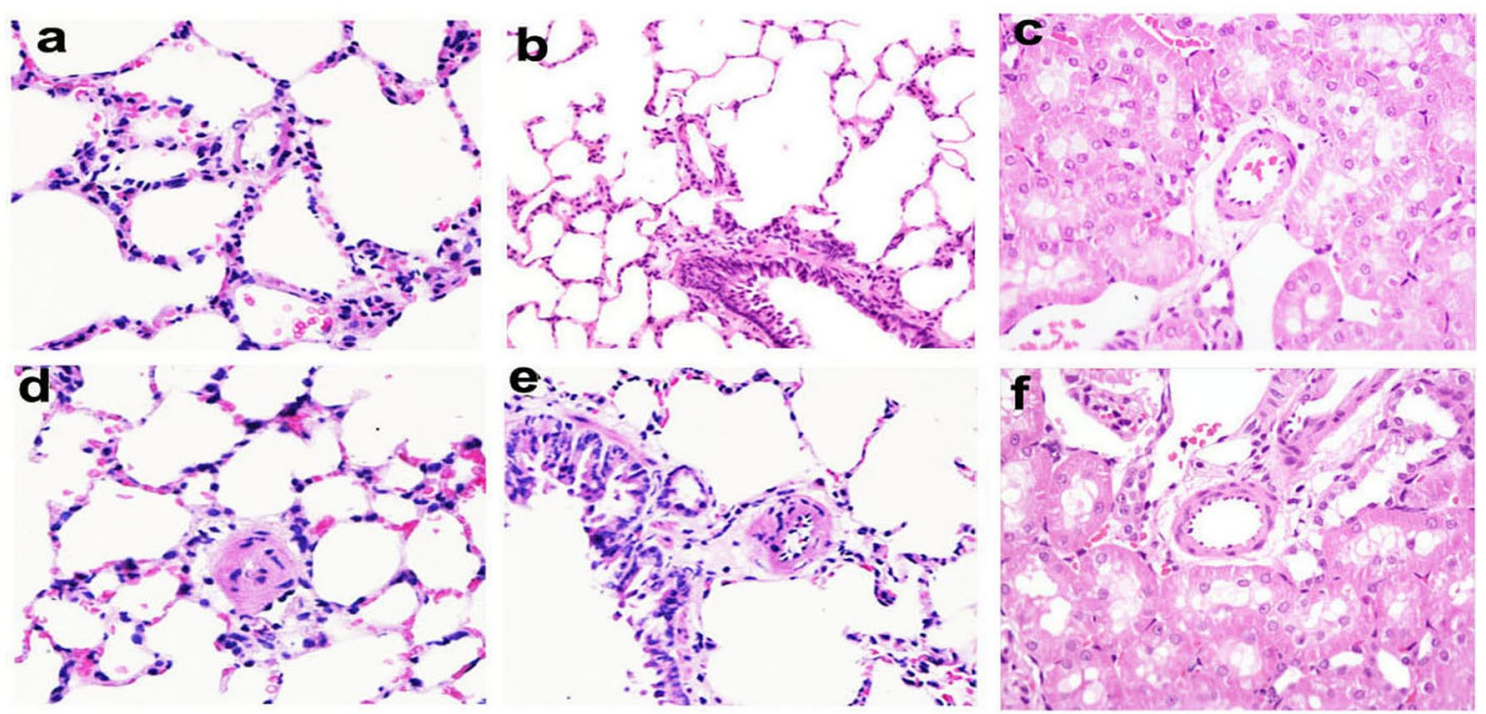

B $a$

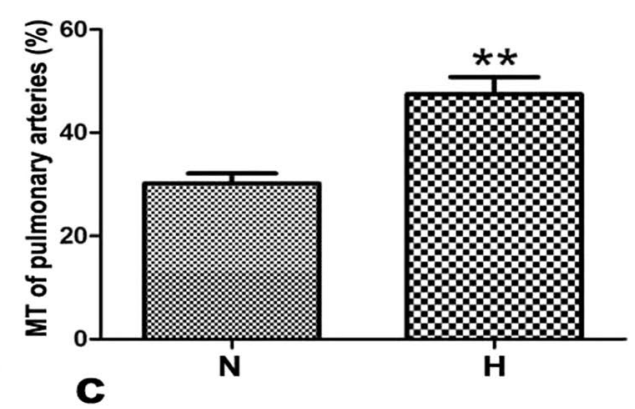

b
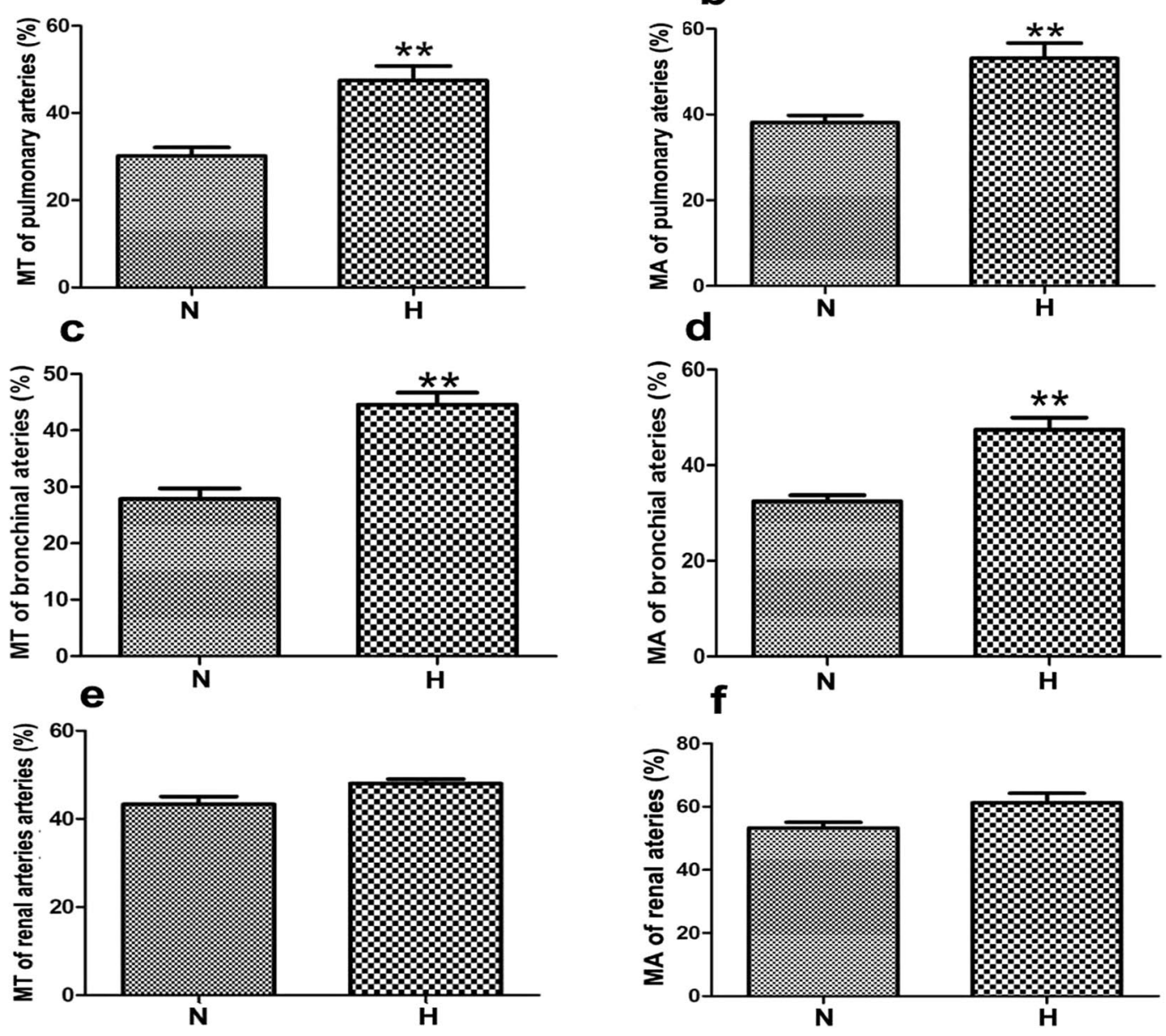

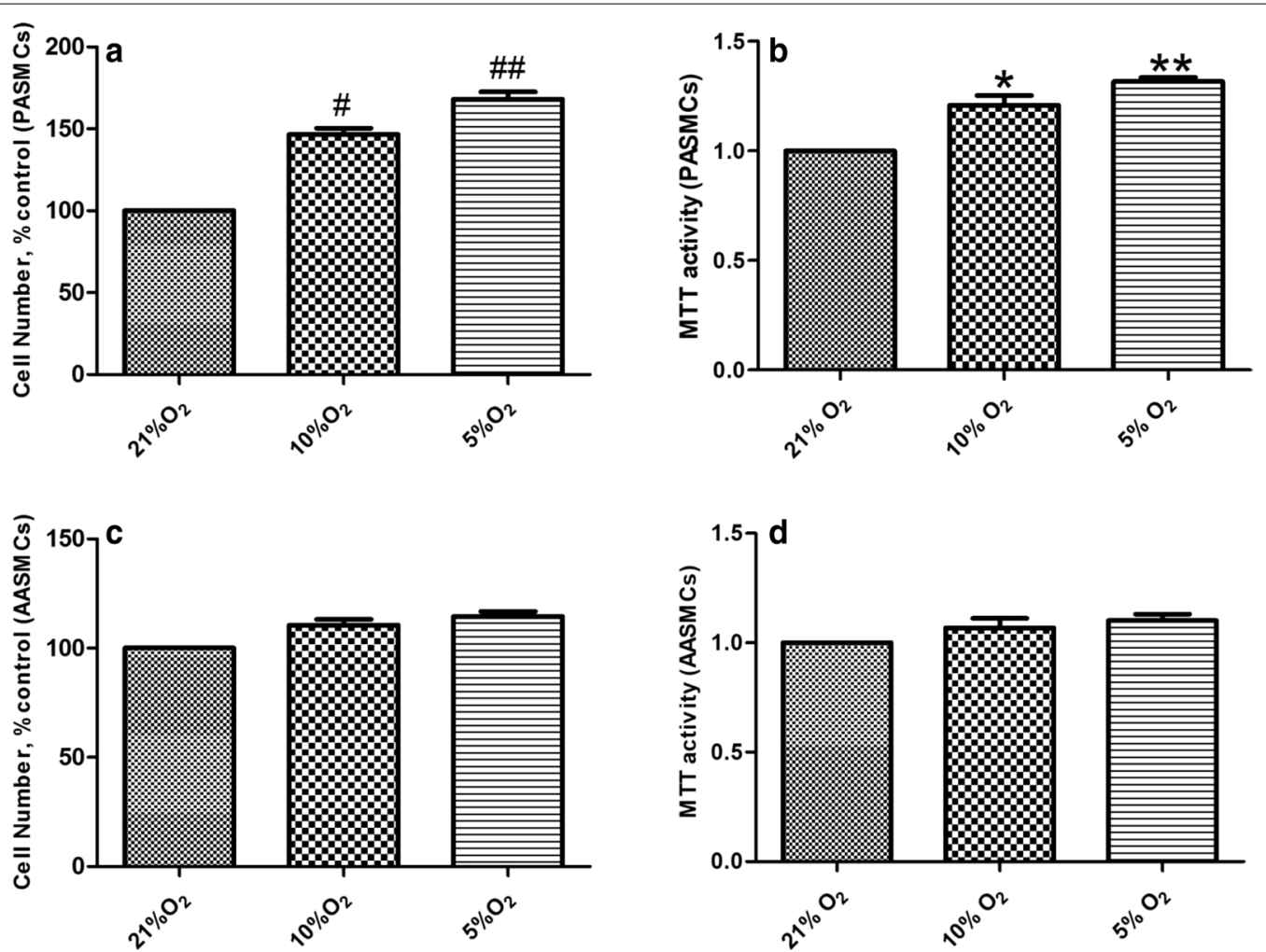

Fig. 3 Effects of hypoxia on proliferation of PASMCs and AASMCs. a and $\mathbf{b}$ Hypoxia promoted the proliferation of PASMCS, $\mathbf{c}$ and $\mathbf{d}$ Hypoxia had no significant effect on the proliferation of AASMCs. Direct cell counting was performed in $\mathbf{a}$ and $\mathbf{c}$, MTT assay was performed in $\mathbf{b}$ and $\mathbf{d}$. The growth of PASMCs or AASMCs under $21 \% \mathrm{O}_{2}$ (control) was set as $100 \%$ and the proliferation of treated cells was calculated as a percentage of them. $n=8$, Data are means \pm S.D. ${ }^{\#} \mathrm{P}<0.05$ or ${ }^{\# \#} \mathrm{P}<0.01$ vs. $21 \% \mathrm{O}_{2},{ }^{*} \mathrm{P}<0.05$ or ${ }^{* *} \mathrm{P}<0.01$ vs. $21 \% \mathrm{O}_{2}$

overnight. The cells were then incubated in serum-free medium for $24 \mathrm{~h}$. Cells were cultured with normoxic $\left(21 \% \mathrm{O}_{2}\right)$ or hypoxic conditions $\left(10 \% \mathrm{O}_{2}\right.$ and $\left.5 \% \mathrm{O}_{2}\right)$, and after $48 \mathrm{~h}$, they were were rinsed with phosphate buffered solution, harvested by mild trypsinization, and counted with a hematocytometer.

\section{MTT assay}

All cells were starved in serum-free medium for $24 \mathrm{~h}$ after growing to subconfluence and then cultured with $5 \%$ fetal bovine serum for $48 \mathrm{~h}$ under normoxic or hypoxic conditions. Subsequently, MTT $(5 \mathrm{mg} / \mathrm{mL})$ was added into the plates $(80 \mu \mathrm{L} /$ well in 24 -well plates or $20 \mu \mathrm{L} /$ well in 96-well plates) and incubated for another $4 \mathrm{~h}$. Dimethyl sulfoxide was added into each well, and all plates were shaken for $10 \mathrm{~min}$ in a shaker. The optical density (OD) values were collected using a spectrophotometer (PowerWave XS, BioTekInc, Winooski, VT).

\section{Quantitative real-time PCR (qRT-PCR)}

qRT-PCR was performed with SYBR PrimeScript ${ }^{\mathrm{TM}}$ RT-PCR kit (TakaRa, Dalian, China). The total RNA of cells was extracted using Trizol (Invitrogen, Carlsbad,
CA, USA). First-strand cDNA was synthesized from RNA. GAPDH was used as an internal control. Primer sequences were designed using the Primer Premier 5.0 software (PREMIER Biosoft International, CA, USA) and synthesized by the DNA Bio Tec (Shanghai, China). Primers sequences used were asfollows: forward: $5^{\prime}-\mathrm{TGG}$ GAAACAACACCCCTATTTT-3' and reverse: 5'-CGA AGATACCACCAGTCGTAGTTG-3' for CAT; forward: CTGTGGCTGAGCTGTTGTAA and reverse: ACAGCG TCCAAGCAATTCAA for $\mathrm{SOD}_{2}$; forward: $5^{\prime}$-CTATCG GCAATGAG CGGTTC-3'and reverse: 5'-GATCTT GATCTTCATGGTGCTAGG-3'for GAPDH.

\section{ROS, $\mathrm{H}_{2} \mathrm{O}_{2}$ and SOD measurement}

PASMCs and AASMCs were stained with an oxidantsensitive fluorescence dye DCFH-DA $(10 \mu \mathrm{mol} / \mathrm{L}$, Nanjing Jian Cheng Bioengineering Institute, Nanjing, China). Subsequently, the intracellular total ROS were detected through fluorescence microscopy (Leica, Heidelberg, Germany) and flow cytometry.

The content of $\mathrm{H}_{2} \mathrm{O}_{2}$ in AECs and AECs culture medium were detected using a commercially available Hydrogen Peroxide Assay Kit (Beyotime Inc, Jiangsu, 

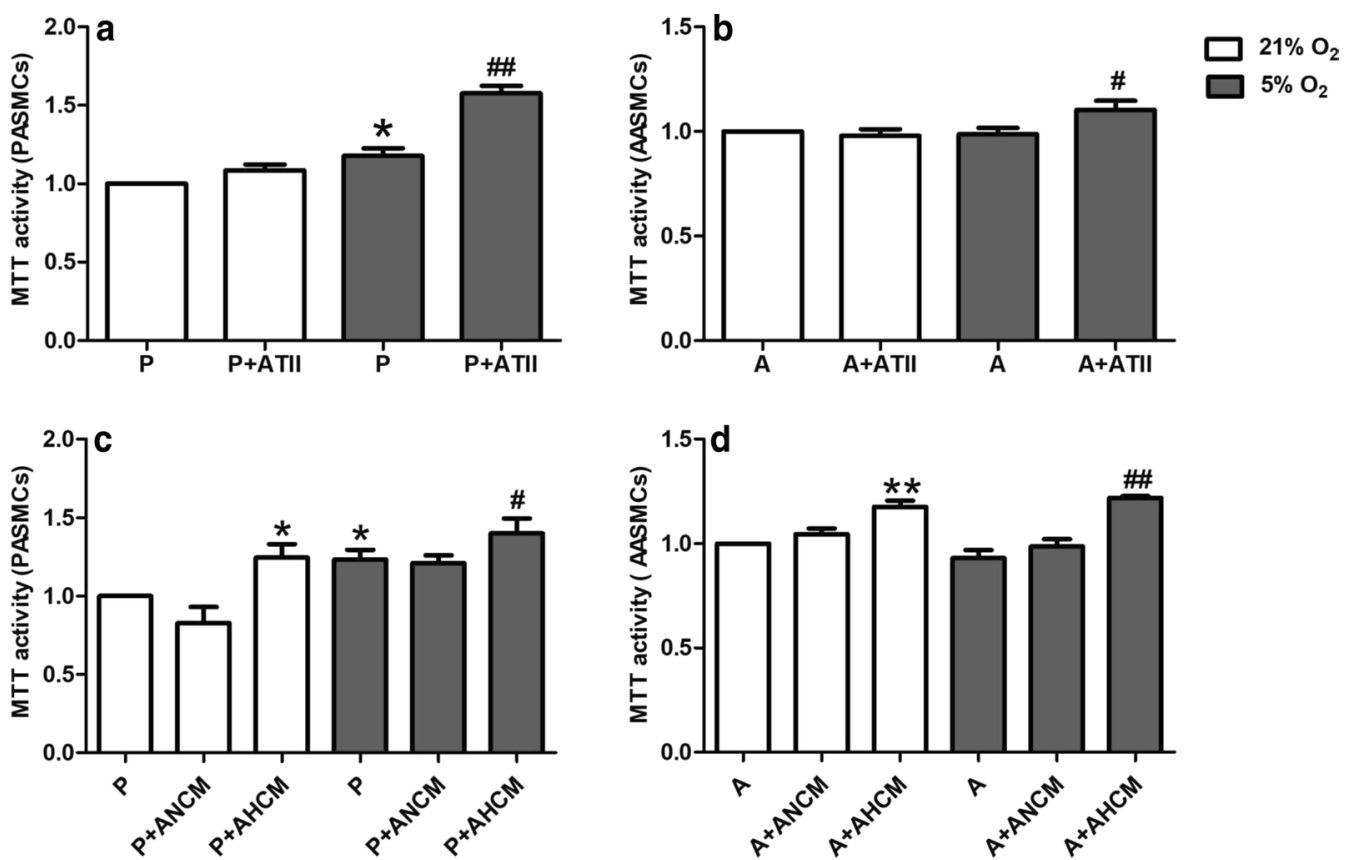

Fig. 4 Effects of AECs on the proliferation of PASMCs and AASMCs under hypoxia. a Co-culture with ATIl significantly promoted the proliferation of PASMCs under hypoxia. ${ }^{*} \mathrm{P}<0.05$ vs. $\mathrm{P}\left(21 \% \mathrm{O}_{2}\right),{ }^{\#} \mathrm{P}<0.01 \mathrm{vs}$. $\mathrm{P}\left(5 \% \mathrm{O}_{2}\right)$. b Co-culture with ATIl significantly promoted the proliferation of AASMCs under hypoxia. ${ }^{\#} \mathrm{P}<0.05$ vs. A $\left(5 \% \mathrm{O}_{2}\right)$. c ATIl hypoxic culture medium significantly promoted the proliferation of PASMCs. ${ }^{*} \mathrm{P}<0.05$ vs. $\mathrm{P}\left(21 \% \mathrm{O}_{2}\right)$,

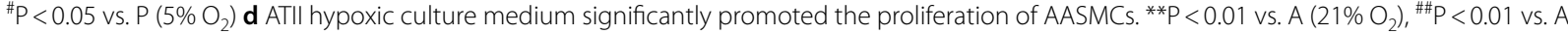
$\left(5 \% \mathrm{O}_{2}\right)$. The growth of PASMCs or AASMCs under $21 \% \mathrm{O}_{2}$ was set as $100 \%$ and the proliferation of treated cells was calculated as a percentage of them. P: PASMCs, A: AASMCs, ANCM ATII normoxic culture medium, AHCM ATIl hypoxic culture medium, $n=8$, Data are means \pm S.D

China) according to the recommended protocols. The concentrations of $\mathrm{H}_{2} \mathrm{O}_{2}$ in different groups were finally normalized to the corresponding protein concentrations.

The content and activity of SOD in AECs were detected using a commercially Tatal Superoxide Dismutase Assay Kit with WST-8 (Beyotime Inc, Jiangsu, China) according to the recommended protocols. The content of SOD in different groups was finally normalized to the corresponding protein concentrations. The activity of SOD is calculated by the formula.

\section{Statistical analysis}

All data were analyzed using SPSS 20.0 software, and represented as average \pm standard deviation (mean $\pm \mathrm{SD}$ ). Analysis of variance (one-way ANOVA) was used for multiple group comparisons, and paired test was used for two group comparisons. A $P$ value $<0.05$ was considered statistically significant.

\section{Results}

\section{Effects of hypoxia on hemodynamics and pulmonary} and systemic arterial wall remodeling

RVSP was measured by catheterization via jugular vein to right ventricle, which substitutes for the pulmonary artery pressure. Compared with normoxic group, the
RVSP (Fig. 1a) and RV/ (LV+S) \% (Fig. 1c) increased significantly in the hypoxia group, while the effect of hypoxia on mCAP was not significant (Fig. 1b). Compared with the normoxia group, the MT\% and MA\% of PA and BA in hypoxic group were significantly increased (Fig. 2a, b). However, hypoxia had no significant effect on the MT\% and MA\% of RA (Fig. 2a, b). Besides, compared with the normoxic group, hypoxia promoted the proliferation of PASMCs (Fig. 3a, b) in vitro, but did not affect the proliferation of AASMCs (Fig. 3c, d). These results indicated that the different responses of pulmonary and systemic arteries to hypoxia might be related to the vascular microenvironment.

\section{Effects of AECs on the proliferation of PASMCs and AASMCs under hypoxia}

To explore the effect of AECs on PASMCs or AASMCs in vitro, the proliferation of PASMCs and AASMCs were detected by MTT. Under normoxia, co-culture with ATII had no significant effect on the proliferation of PASMCs and AASMCs compared with those co-cultured without ATII (Fig. 4a, b), However, co-culture with ATII significantly promoted the proliferation of PASMCs and AASMCs compared with those co-cultured without ATII under hypoxia (Fig. 4a, b). To further clarify 

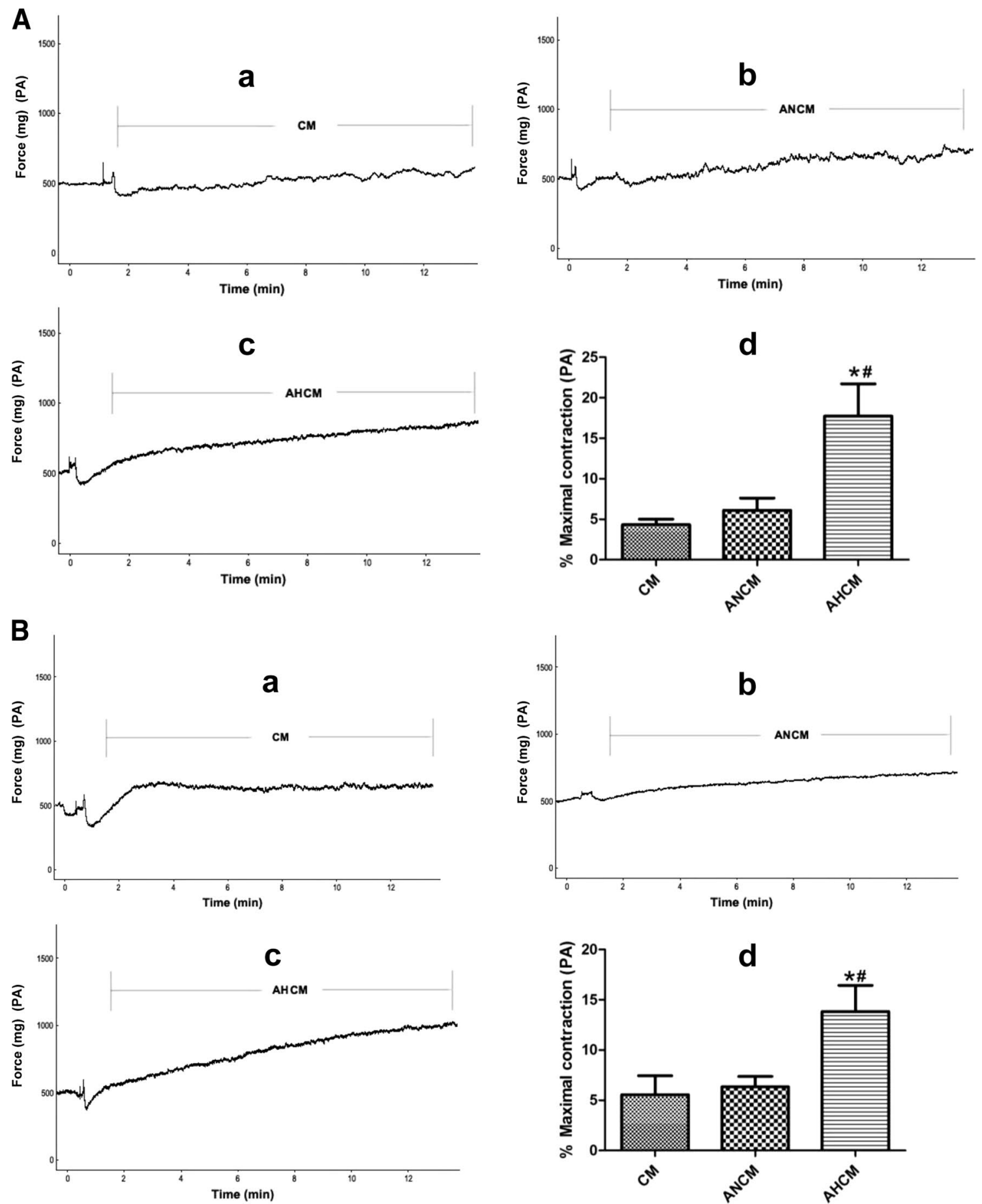

Fig. 5 Effects of AECs conditioned culture medium on the constriction of PA ring. A ATIl hypoxic hypoxic culture medium significantly promoted the constriction of PA ring from normoxic rats $(\mathbf{a}-\mathbf{c})$ the representative curve for the effect of culture medium, ATIl normoxic and hypoxic culture medium on the constriction of PA ring from normoxic rats (d) the summarized data of PA ring maximum constriction. $\mathbf{B}$ ATII hypoxic culture medium significantly promoted the constriction of PA ring from HPH rats $(\mathbf{a}-\mathbf{c})$ the representative curve for the effect of culture medium, ATII normoxic and hypoxic culture medium on the constriction of PA ring from HPH rats (d) the summarized data of PA ring maximum constriction. CM culture medium, ANCM ATII normoxic culture medium, AHCM ATIl hypoxic culture medium, $n=5$, Data are means $\pm S . D$. ${ }^{*} P<0.05$ vs. $C M$, $\#$ P $<0.05$ vs. ANCM 
the effect of AECs on the proliferation of PASMCs or AASMCs, the culture medium of PASMCs and AASMCs were replaced with AECs conditioned culture medium. Under normoxia, the normoxic culture medium of ATII had no significant effect on the proliferation of PASMCs and AASMCs compared with those co-cultured without ATII culture medium (Fig. 4c, d). However, ATII hypoxic culture medium significantly promoted the proliferation of PASMCs and AASMCs compared with those co-cultured without ATII culture medium (Fig. 4c, d). Under hypoxia, the normoxic culture medium of ATII had no significant effect on the proliferation of PASMCs and AASMCs compared with those co-cultured without ATII culture medium (Fig. 4c, d). However, ATII hypoxic culture medium significantly promoted the proliferation of PASMCs and AASMCs compared with those co-cultured without ATII culture medium (Fig. 4c, d). These data indicated that AECs could promote the proliferation of PASMCs and AASMCs in hypoxia.

\section{Effects of AECs conditioned culture medium on the constriction of $P A$ and $A A$ rings}

To explore whether AECs culture medium could regulate PA and AA rings, we further examined the effects of AECs culture medium on PA or AA rings from normoxic and $\mathrm{HPH}$ rats. For normoxic rats, the normoxic culture medium from ATII had no significant effect on the constriction of PA (Fig. 5a) and AA rings (Fig. 6a) compared with the culture medium group. However, the hypoxic culture medium from ATII significantly promoted the constriction of PA (Fig. 5a) and AA rings (Fig. 6a) compared with the culture medium or the normoxic culture medium group. For HPH rats, the normoxic culture medium from ATII had no significant effect on the constriction of PA (Fig. 5b) and AA rings (Fig. 6b) compared with the culture medium group. However, the hypoxic culture medium from ATII significantly promoted the constriction of PA (Fig. 5b) and AA rings (Fig. 6b) compared with the culture medium or the normoxic culture medium group. These results indicated that AECs hypoxic culture medium could induce the constriction of $\mathrm{PA}$ and AA.

\section{Effects of hypoxia on ROS in AECs}

To explore the possible mechanism involved the effect of AECs on the proliferation of PASMCs and AASMCs and the constriction of PA and AA, total intracellular ROS was detected through DCFH-DA, and $\mathrm{H}_{2} \mathrm{O}_{2}$ in AECs and the culture medium were determined by commercial kit. Hypoxia significantly increased the production of ROS and $\mathrm{H}_{2} \mathrm{O}_{2}$ in AECs and AECs culture medium (Fig. 7a). Meanwhile, we examined mRNA level of $S O D 2$ and $C A T$ , and detected the total level and activity of SOD in AECs by commercial kits. Hypoxia significantly increased the SOD2 mRNA of (Fig. 7b) and the total level and activity of SOD (Fig. 7b). However, hypoxia has no significant effect on the CAT mRNA (Fig. 7b). These results indicated that the increase of ROS and $\mathrm{H}_{2} \mathrm{O}_{2}$ in AECs may be caused by imbalance of SOD2 and CAT in hypoxia.

\section{Effects of exogenous $\mathrm{H}_{2} \mathrm{O}_{2}$ and NAC intervention on the proliferation of PASMCs and AASMCs and the constriction of $P A$ and $A A$ rings}

Some studies have reported that the effects of different concentrations of $\mathrm{H}_{2} \mathrm{O}_{2}$ on cell proliferation were different. We used exogenous $0-1000 \mu \mathrm{M} \mathrm{H}_{2} \mathrm{O}_{2}$ to observe how $\mathrm{H}_{2} \mathrm{O}_{2}$ affects the proliferation of PASMCs andAASMCs under normoxia. The results showed that $0-50 \mu \mathrm{M} \mathrm{H}_{2} \mathrm{O}_{2}$ increased the proliferation of PASMCs in a dose-dependent manner. However, the proliferation of PASMCs was then gradually inhibited by 100 $1000 \mu \mathrm{M} \mathrm{H}_{2} \mathrm{O}_{2}$ (Fig. 8a). Similarly, $\mathrm{H}_{2} \mathrm{O}_{2}(0-100 \mu \mathrm{M})$ also led to a dose-dependent increase in the proliferation of AASMCs, while $\mathrm{H}_{2} \mathrm{O}_{2}(200-1000 \mu \mathrm{M})$ inhibited the proliferation of AASMCs (Fig. 8b). To test the effect of NAC on PASMCs or AASMCs proliferation, we chose $50 \mu \mathrm{M}$ and $100 \mu \mathrm{M} \mathrm{H}_{2} \mathrm{O}_{2}$, which mostly promoted the proliferation of PASMCs and AASMCs, respectively. The results showed that NAC ( $5 \mathrm{mM}$ and $10 \mathrm{mM}$ ) effectively inhibited the proliferation of PASMCs and AASMCs, and $10 \mathrm{mM}$ NAC was more effective (Fig. 8c, d).

Exogenous $\mathrm{H}_{2} \mathrm{O}_{2}(5-1000 \mu \mathrm{M})$ was used to explore whether $\mathrm{H}_{2} \mathrm{O}_{2}$ affects the constriction of PA and AA rings in normal rats. The results showed that $5-400 \mu \mathrm{M}$ $\mathrm{H}_{2} \mathrm{O}_{2}$ increased the constriction of PA ring in a dosedependent manner, while the constriction of PA ring was gradually inhibited by $600-1000 \mu \mathrm{M} \mathrm{H}_{2} \mathrm{O}_{2}$ (Fig. 9a). Similarly, $\mathrm{H}_{2} \mathrm{O}_{2}(5-600 \mu \mathrm{M})$ also increased the constriction of

\section{(See figure on next page.)}

Fig. 6 Effects of AECs conditioned culture medium on the constriction of AA ring. A ATIl hypoxic culture medium significantly promoted the constriction of AA ring from normoxic rats, $(\mathbf{a}-\mathbf{c})$ the representative curve for the effect of culture medium, ATII normoxic and hypoxic culture medium on the constriction of AA ring from normoxic rats, (d) the summarized data of AA ring maximum constriction. B ATII hypoxic culture medium significantly promoted the constriction of AA ring from HPH rats, $(\mathbf{a}-\mathbf{c})$ the representative curve for the effect of culture medium, ATII normoxic and hypoxic culture medium on the constriction of AA ring from HPH rats, (d) the summarized data of AA ring maximum constriction. CMculture medium, ANCM ATII normoxic culture medium, AHCM ATIl hypoxic culture medium, $n=5$, Data are means $\pm S . D$. ${ }^{*} P<0.05$ vs. CM, \#P $<0.05$ vs. ANCM 
Wang et al. Respir Res $\quad$ (2021) 22:134

Page 10 of 16
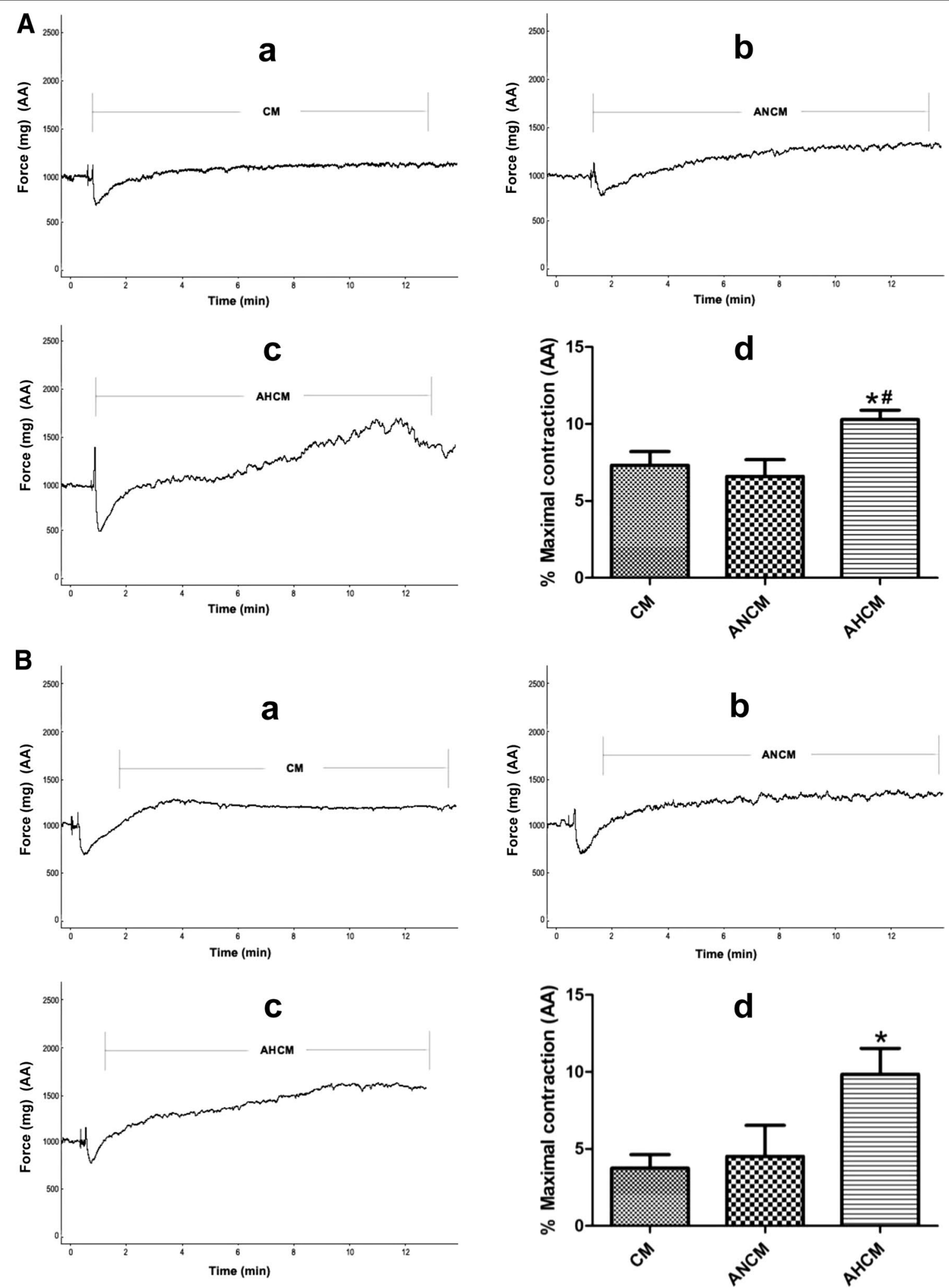

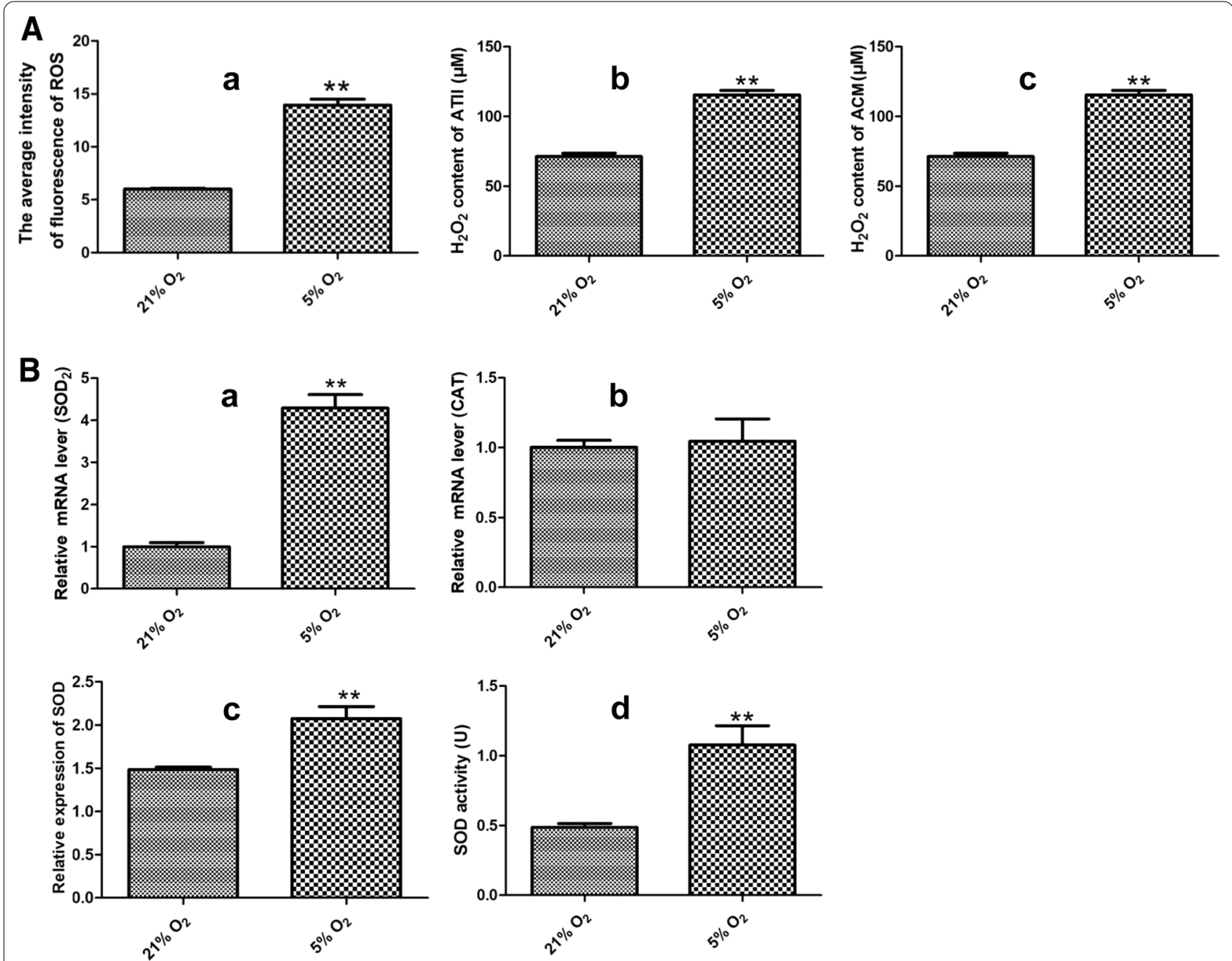

Fig. 7 Effect of hypoxia on ROS in AECs. A Hypoxia significantly increased the intensity of ROS (a) and the content of $\mathrm{H}_{2} \mathrm{O}_{2}$ (b) in $\mathrm{ATIl}$ and the content of $\mathrm{H}_{2} \mathrm{O}_{2}$ in ATIl culture medium (c). (B) Hypoxia significantly increased SOD2 mRNA level (a), the total content of SOD (c) and the activity of $\mathrm{SOD}$ (d) of ATIl, but has no significant effect on the CAT mRNA level (b). $\mathrm{n}=3$, Data are means \pm S.D. ACM ATIl culture medium ${ }^{* *} P<0.01$ vs. $21 \% \mathrm{O}_{2}$

AA rings in dose-dependent manner, and then inhibited the constriction of AA ring at $800-1000 \mu \mathrm{M}$ (Fig. 9a). To test the effect of NAC on PA and AA rings constriction, we then chose $400 \mu \mathrm{M}$ and $600 \mu \mathrm{M} \mathrm{H}_{2} \mathrm{O}_{2}$, both of which mostly affected the constriction of PA (Fig. 9b) and AA rings (Fig. 9b), respectively. The results showed that $10 \mathrm{mM}$ NAC effectively inhibited the constriction of PA and AA (Fig. 9b).

\section{Effects of NAC intervention on the proliferation of PASMCs and $A A S M C s$ and the constriction of $P A$ and $A A$ rings}

The concentration of $\mathrm{H}_{2} \mathrm{O}_{2}$ in AECs cell culture medium at $24 \mathrm{~h}$ under hypoxia was detected which was found to be within the range of promoting cell proliferation. The NAC intervention was performed in the co-culture system, which showed that both the proliferation of PASMCs (Fig. 10a) and AASMCs (Fig. 10a) were effectively inhibited by $10 \mathrm{mM}$ NAC. These results indicated that $\mathrm{H}_{2} \mathrm{O}_{2}$ from ATII was involved in the proliferation of PASMCs and AASMCs. Besides, the concentration of $\mathrm{H}_{2} \mathrm{O}_{2}$ in AECs culture medium for $24 \mathrm{~h}$ under hypoxia was within the range of promoting constriction. Additionally, the constriction of PA (Fig. 10b) and AA rings (Fig. 10b) were effectively inhibited by $10 \mathrm{mM}$ NAC. These results demonstrated that $\mathrm{H}_{2} \mathrm{O}_{2}$ from ATII was involved in the constriction of PA and AA.

\section{Discussion}

It is well-known that pulmonary and systemic vessels respond differently to hypoxia and even more that isolated SMC can respond to hypoxia differently according to its origin [29]. Consistently, in this study we also confirmed that PA and RA respond differently to hypoxia and even more that PASMCs and AASMCs can respond 

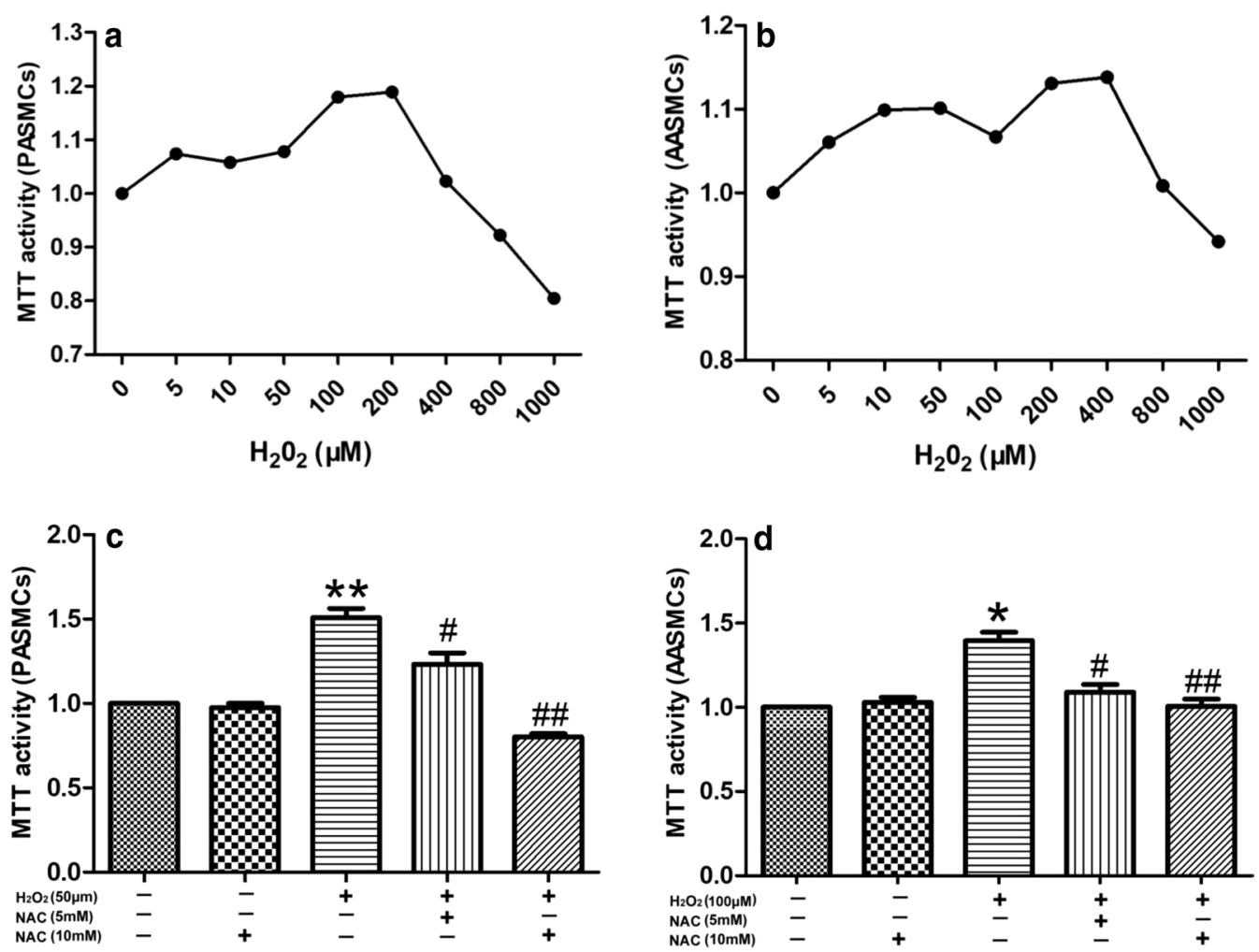

Fig. 8 Effects of exogenous $\mathrm{H}_{2} \mathrm{O}_{2}$ and NAC intervention on the proliferation of PASMCs and AASMCs. a The effects of exogenous $\mathrm{H}_{2} \mathrm{O}_{2}$ on the

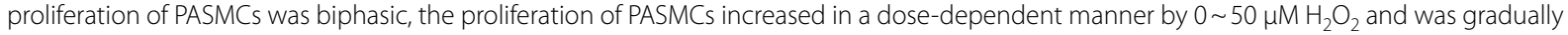
inhibited by $100 \sim 1000 \mu \mathrm{M} \mathrm{H}_{2} \mathrm{O}_{2}$. b The effects of exogenous $\mathrm{H}_{2} \mathrm{O}_{2}$ on the proliferation of AASMCs was biphasic, the proliferation of AASMCs increased in a dose-dependent manner by $0 \sim 100 \mu \mathrm{M} \mathrm{H}_{2} \mathrm{O}_{2}$ and was gradually inhibited by $200 \sim 1000 \mu \mathrm{M} \mathrm{H}_{2} \mathrm{O}_{2}$. $\mathbf{a}$ and $\mathbf{b}$ The cell growth of $0 \mu \mathrm{M}$ $\mathrm{H}_{2} \mathrm{O}_{2}$ group was set as $100 \%$ and the proliferation of treated cells was calculated as a percentage of them. $n=8$, Data are means \pm S.D. ${ }^{* *} \mathrm{P}<0.01$ or ${ }^{*} \mathrm{P}<0.05$ vs. $0 \mu \mathrm{M} \mathrm{H}_{2} \mathrm{O}_{2} . \mathbf{c} 5 \mathrm{mM}$ and $10 \mathrm{mM}$ NAC effectively inhibited the proliferation of PASMCs induced by $50 \mu M \mathrm{H}_{2} \mathrm{O}_{2}$. ${ }^{* *} \mathrm{P}<0.01$ vs. without any treatment group, ${ }^{\# \#} \mathrm{P}<0.01$ or ${ }^{\#} \mathrm{P}<0.05$ vs. treatment with $50 \mu \mathrm{M} \mathrm{H}_{2} \mathrm{O}_{2}$ alone group. $\mathbf{d} 5 \mathrm{mM}$ and $10 \mathrm{mM}$ NAC effectively inhibited the proliferation of AASMCs induced by $100 \mu \mathrm{M} \mathrm{H}_{2} \mathrm{O}_{2}$. ${ }^{*} \mathrm{P}<0.05$ vs. without any treatment group, ${ }^{\# \#} \mathrm{P}<0.01$ or ${ }^{\#} \mathrm{P}<0.05$ vs. treatment with $100 \mu \mathrm{M} \mathrm{H} \mathrm{H}_{2} \mathrm{O}_{2}$ alone group. (c and $\mathbf{d}$ ) The cell growth of the group without any treatment was set as $100 \%$ and the proliferation of treated cells was calculated as a percentage of them. $n=8$, Data are means $\pm S$

to hypoxia differently. But we found that BA had the same response to hypoxia as PA in remodeling. Thus, we proposed the pulmonary vascular microenvironment created by AECs would be involved in the pulmonary vascular remodeling and constriction. In vitro, we showed that AECs not only promoted the proliferation of PASMCs, but also promoted the proliferation of AASMCs under hypoxia. And the hypoxic culture medium of AECs promoted the constriction of PA and AA rings. Furthermore, our data imply a role of regulation of AECs production of $\mathrm{H}_{2} \mathrm{O}_{2}$ depending on the pathway of ROS/ SOD2 as a possible mechanism of the regulation in the pulmonary vascular remodeling and constriction.

Some studies have confirmed that the response of the pulmonary vascular system to hypoxia is vasoconstriction rather than vasodilation in the systemic circulation $[8,30,31]$. Though BA belong to systemic circulation vessel, they are also exposed to AECs-related pulmonary vascular microenvironment. So in this study we found that PA and BA both show remodeling during alveolar hypoxia. A previous study comfirmed that alveolar hypoxia can cause hypoxic pulmonary vascular remodeling and vasoconstriction, and hypoxemia can not [30]. In the case of ventilatory dysfunction and low oxygen in the plateau, AECs primarily sense alveolar hypoxia and suffer the most dramatic changes in oxygen partial pressure. Therefore, we thought that AECs should play an important role in $\mathrm{HPH}$. In our study, we observed the hemodynamic and morphological data of PA, BA and RA by constructing rat model of $\mathrm{HPH}$. The results showed that hypoxia significantly increased RVSP, RV/ $(\mathrm{LV}+\mathrm{S}) \%, \mathrm{MT} \%$ and $\mathrm{MA} \%$ of PA and BA, but had no significant effect on mCAP, MT\% and MA\% of RA. In addition, co-culture with AECs and treatment with AECs 


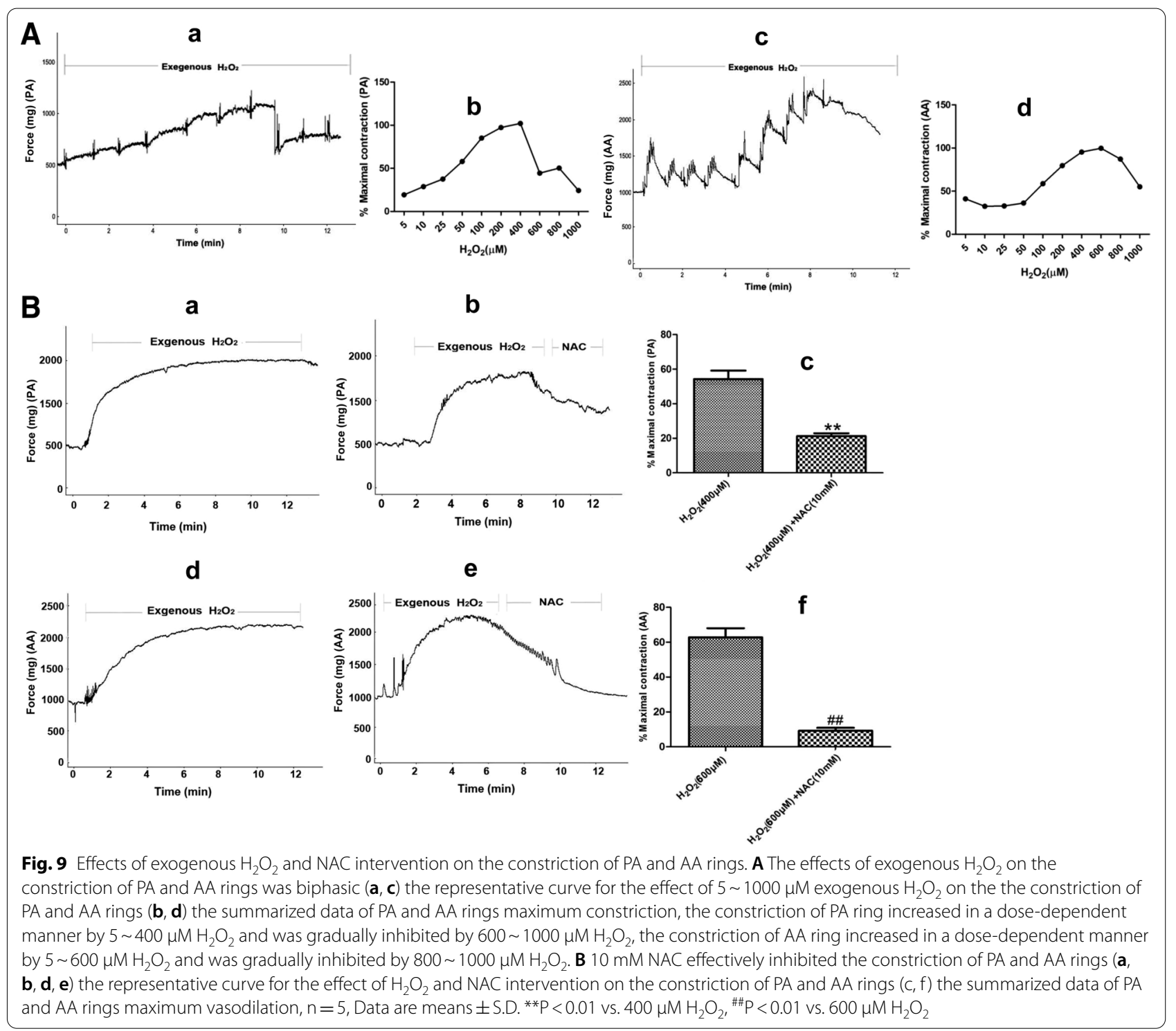

hypoxic culture medium not only significantly promoted PASMCs proliferation and PA constriction, but also significantly promoted AASMCs proliferation and AA constriction. Therefore, our data indicate that AECs play a key role in HPH and even more that the systemic vessel in the AECs-related microenvironment had also undergone remodeling and constriction.

It is interesting to consider the regulation of key antioxidant enzymes such as SOD and CAT in evaluating the role of redox-regulating signaling in pulmonary vascular diseases [32]. SOD can catalyze the rapid dismutation of $\mathrm{O} 2$ - to $\mathrm{H}_{2} \mathrm{O}_{2}$ and molecular oxygen, however, CAT can catalyzes the two-stage conversion of $\mathrm{H}_{2} \mathrm{O}_{2}$ to water and oxygen [32]. $\mathrm{H}_{2} \mathrm{O}_{2}$ is a stable and easily diffused out of the cell [18]. SOD has three isoforms, which are located in the cytosol (SOD1), mitochondria (SOD2) or extracellular compartment (SOD3), respectively [33]. Accumulating evidence has suggested that impaired activity of SOD2 and SOD3 contributed to pulmonary hypertension, and the level and activity of SOD1 has not been found significantly changed in human pulmonary hypertension [34, 35]. In this study, we found that hypoxia significantly increased the mRNA level of SOD2 and the content and activity of total SOD in AECs, while hypoxia has no significant effect on mRNA level of CAT. And the content of ROS and $\mathrm{H}_{2} \mathrm{O}_{2}$ in AECs and AECs culture medium also were increase under hypoxia. Hence, our data suggest that $\mathrm{H}_{2} \mathrm{O}_{2}$ derived from AECs can affect pulmonary vascular microenvironment and $\mathrm{H}_{2} \mathrm{O}_{2}$ may be 


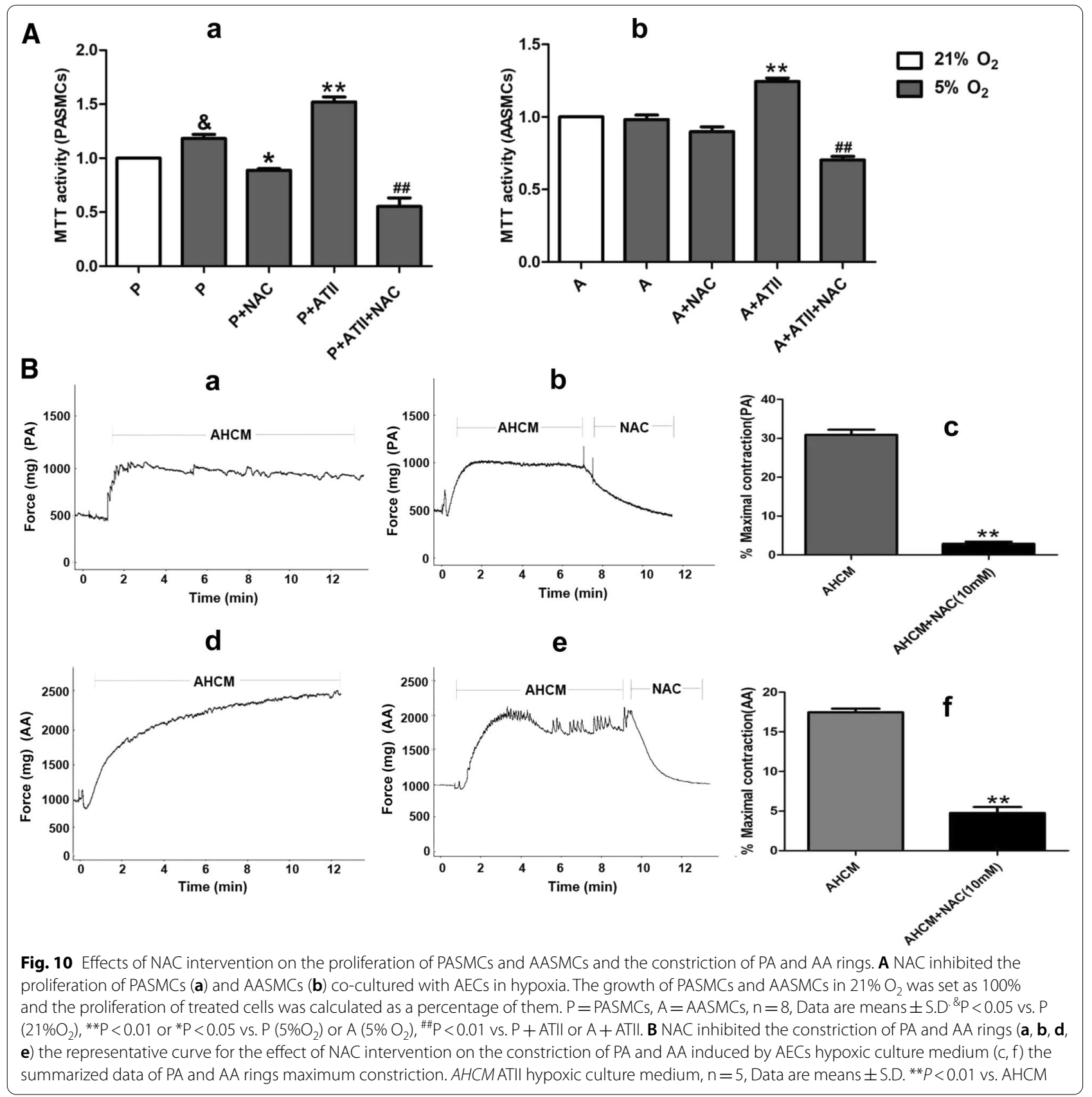

caused by imbalance of SOD2 and CAT in AECs under hypoxia.

It has recently been reported that that $\mathrm{H}_{2} \mathrm{O}_{2}$ can regulate a variety of cellular functions, including proliferation, differentiation, and more generally gene expression [36, 37]. However, data on the basal concentrations of $\mathrm{H}_{2} \mathrm{O}_{2}$ and the thresholds for cell proliferation are limited. Studies have shown that treatment with a continuous extracellular source of $\mathrm{H}_{2} \mathrm{O}_{2}$ increases cell proliferation [26, 38]. Here, we determined the concentration range of $\mathrm{H}_{2} \mathrm{O}_{2}$ that promoted the proliferation of PASMCs and AASMCs. We found that the $\mathrm{H}_{2} \mathrm{O}_{2}$ produced by AECs cells was within the concentration range. Co-culture with AECs under hypoxic and the intermittent replacement of AECs hypoxic culture medium which were consistent with the conditions of continuous extracellular source of $\mathrm{H}_{2} \mathrm{O}_{2}$ can induce PASMCs and AASMCs proliferation. In other words, the method described above effected the proliferation of PASMCs and AASMCs 
by changing the microenvironment of PASMCs and AASMCs. In addition, NAC intervention reduced the proliferation PASMCs and AASMCs by co-culture with AECs under hypoxia. These results further indicate that $\mathrm{H}_{2} \mathrm{O}_{2}$ derived from AECs play an important role in PASMCs and AASMCs proliferation under hypoxia. Jin et al. [39] reported that exposure to $\mathrm{H}_{2} \mathrm{O}_{2}$ could cause smooth muscle constriction and dysfunction in isolated PA. Here, we also determined the concentration range of $\mathrm{H}_{2} \mathrm{O}_{2}$ that promoted the constriction of PA and AA. Similarly, the $\mathrm{H}_{2} \mathrm{O}_{2}$ produced by AECs during hypoxia was within the concentration range. The hypoxic culture medium of AECs promoted PA and AA rings constriction, and NAC intervention alleviated this effect. These results indicate that $\mathrm{H}_{2} \mathrm{O}_{2}$ derived from AECs plays an important role in the constriction of PA and AA. Taken together, our results could indicate that AECs are involved in remodeling and constricting of pulmonary vessels by releasing $\mathrm{H}_{2} \mathrm{O}_{2}$ under hypoxia and could explain the similar response of systemic arteries and AASMCs during treatment with AECs hypoxic culture medium and co-culture with AECs in vitro, respectively.

\section{Conclusion}

The proliferation of PASMCs and the constriction of PA are critical to the development of HPH. Our study showed that the pulmonary vascular microenvironment was conducive to $\mathrm{HPH}$, and AECs played a vital role in constructing the pulmonary vascular microenvironment. The continuous extracellular source of ROS is necessary for inducing PASMCs proliferation and PA constriction. $\mathrm{H}_{2} \mathrm{O}_{2}$ derived from AECs could affect the pulmonary vascular microenvironment and were involved in pulmonary vascular remodeling and constriction of $\mathrm{HPH}$.

\footnotetext{
Abbreviations

HPH: Hypoxic pulmonary hypertension; AECs: Alveolar epithelial cells; PA: Pulmonary artery; AA: Aortic artery; RA: Renal artery; PASMCs: Pulmonary artery smooth cells; AASMCs: Aortic artery smooth cells; mCAP: Mean carotid artery pressure; RV: Right ventricle; LV + S: Left ventricle plus septum; MT: Medial wall thickness; MA: Medial wall area; FBS: Fetal bovine serum; RVSP: Right ventricle peak systolic pressure; SOD: Superoxide dismutase; CAT: Catalase; ROS: Reactive oxygen species; $\mathrm{H}_{2} \mathrm{O}_{2}$ : Hydrogen peroxide; NAC: N-acetylcysteine; CM: Culture medium; ANCM: ATII normoxic culture medium; AHCM: ATII hypoxic culture medium
}

\section{Authors' contributions}

$Y W$ and $X L$ contributed to the experimental design and overall experimentation, WN, JC, BZ, XZ, YW conceptualized the project and data analysis, ZL and SD contributed to the experimental design, funding, and writing of the manuscript. All authors read and approved the final manuscript.

\section{Funding}

This present study was funded by the National Nature Science Foundation of China (Grant Nos. 31670328, 81800046, 82070054, 81471816, 81571839 and 81200036) and the Science and Technology Research and Development Program of Shaanxi Province, China (No. 2019SF-008).

\section{Availability of data and materials}

We would like to share part of our data, because some of our data will be used in future research.

\section{Declarations}

\section{Ethics approval and consent to participate}

The study was approved and supervised by the Medical Research Ethics Committee of the Fourth Military Medical University. All participants fully understood the information files. Informed consent was obtained from all participants. All experiments were performed in accordance with the relevant guidelines and regulations. The animal protocol has been reviewed and approved by the Institutional Animal Care and Use Committee (IACUC), the Fourth Military Medical University, China.

\section{Consent for publication}

Not applicable.

\section{Competing interests}

The authors declare that they have no competing interests.

\section{Author details}

${ }^{1}$ Department of Pathology, Xijing Hospital and School of Basic Medicine, Fourth Military Medical University, Xi'an, Shaanxi 710032, People's Republic of China. ${ }^{2}$ Department of Pathophysiology, School of Basic Medicine, Fourth Military Medical University, 169 Changle Western Street, Xi'an, Shaanxi 710032, People's Republic of China. ${ }^{3}$ Northwest University School of Medicine, Xi'an, Shaanxi 710075, People's Republic of China. ${ }^{4}$ Department of Respiratory and Critical Care, Tangdu Hospital, Fourth Military Medical University, 569 Xinsi Street, Xi'an, Shaanxi 710038, People's Republic of China. ${ }^{5}$ Department of Pathophysiology, Xi'an Peihua University, Xi'an, Shaanxi 710032, People's Republic of China.

Received: 11 December 2020 Accepted: 8 April 2021

Published online: 04 May 2021

\section{References}

1. Barbera JA, Blanco I. Pulmonary hypertension in patients with chronic obstructive pulmonary disease: advances in pathophysiology and management. Drugs. 2009;69:1153-71.

2. Penaloza D, Arias-Stella J. The heart and pulmonary circulation at high altitudes: healthy highlanders and chronic mountain sickness. Circulation. 2007;115:1132-46.

3. Wilkins MR, Ghofrani HA, Weissmann N, Aldashev A, Zhao L. Pathophysiology and treatment of high-altitude pulmonary vascular disease. Circulation. 2015;131:582-90.

4. Yan D, Li G, Zhang Y, Liu Y. Angiotensin-converting enzyme 2 activation suppresses pulmonary vascular remodeling by inducing apoptosis through the Hippo signaling pathway in rats with pulmonary arterial hypertension. Clin Exp Hypertens. 2019;41:589-98.

5. Liu M, Wang Y, Zheng L, Zheng W, Dong K, Chen S, Zhang B, Li Z. Fasudil reversedMCT-inducedand chronic hypoxia-induced pulmonary hypertension by attenuating oxidative stress and inhibiting the expression of Trx1 and HIF-1alpha. Respir Physiol Neurobiol. 2014;201:38-46.

6. Zakynthinos E, Daniil Z, Papanikolaou J, Makris D. Pulmonary hypertension in COPD: pathophysiology and therapeutic targets. Curr Drug Targets. 2011;12:501-13

7. Wang LN, Yu WC, Du CH, Tong L, Cheng ZZ. Hypoxia is involved in hypoxic pulmonary hypertension through inhibiting the activation of FGF2 by miR-203. Eur Rev Med Pharmacol Sci. 2018;22:8866-76.

8. Boger R, Hannemann J. Dual role of the L-arginine-ADMA-NO pathway in systemic hypoxic vasodilation and pulmonary hypoxic vasoconstriction. Pulm Circ. 2020:10:2045894020918850.

9. Hough RF, Bhattacharya S, Bhattacharya J. Crosstalk signaling between alveoli and capillaries. Pulm Circ. 2018;8:2045894018783735. 
10. Signorelli S, Jennings $P$, Leonard MO, Pfaller W. Differential effects of hypoxic stress in alveolar epithelial cells and microvascular endothelial cells. Cell Physiol Biochem. 2010;25:135-44.

11. Makino A, Firth AL, Yuan JX. Endothelial and smooth muscle cell ion channels in pulmonary vasoconstriction and vascular remodeling. Compr Physiol. 2011;1:1555-602.

12. Zhu P, Huang $L, G e X$, Yan F, Wu R, Ao Q. Transdifferentiation of pulmonary arteriolar endothelial cells into smooth muscle-like cells regulated by myocardin involved in hypoxia-induced pulmonary vascular remodelling. Int J Exp Pathol. 2006;87:463-74.

13. Luo Y, Dong HY, Zhang B, Feng Z, Liu Y, Gao YQ, Dong MQ, Li ZC. miR29a-3p attenuates hypoxic pulmonary hypertension by inhibiting pulmonary adventitial fibroblast activation. Hypertension. 2015;65:414-20.

14. Gore B, Izikki M, Mercier O, Dewachter L, Fadel E, Humbert M, Dartevelle $P$, Simonneau G, Naeije R, Lebrin F, Eddahibi S. Key role of the endothelial TGF-beta/ALK1/endoglin signaling pathway in humans and rodents pulmonary hypertension. PLoS ONE. 2014;9:e100310.

15. Grimmer B, Kuebler WM. The endothelium in hypoxic pulmonary vasoconstriction. J Appl Physiol. 1985;2017(123):1635-46.

16. Smith KA, Schumacker PT. Sensors and signals: the role of reactive oxygen species in hypoxic pulmonary vasoconstriction. J Physiol. 2019:597:1033-43.

17. Bonnet $\mathrm{S}$, Boucherat $\mathrm{O}$. The ROS controversy in hypoxic pulmonary hypertension revisited. Eur Respir J. 2018. https://doi.org/10.1183/13993 003.00276-2018.

18. Xu Z, Rothstein SJ. ROS-Induced anthocyanin production provides feedback protection by scavenging ROS and maintaining photosynthetic capacity in Arabidopsis. Plant Signal Behav. 2018;13:e1451708.

19. Zuo L, Chuang CC, Clark AD, Garrison DE, Kuhlman JL, Sypert DC. Reactive oxygen species in COPD-related vascular remodeling. Adv Exp Med Biol. 2017;967:399-411.

20. Jaitovich A, Jourd'heuil D. A brief overview of nitric oxide and reactive oxygen species signaling in hypoxia-induced pulmonary hypertension. Adv Exp Med Biol. 2017;967:71-81.

21. Roberto D, Micucci P, Sebastian T, Graciela F, Anesini C. Antioxidant activity of limonene on normal murine lymphocytes: relation to $\mathrm{H} 2 \mathrm{O} 2$ modulation and cell proliferation. Basic Clin Pharmacol Toxicol. 2010;106:38-44.

22. Hwang JW, Kim EK, Lee SJ, Kim YS, Moon SH, Jeon BT, Sung SH, Kim ET, Park PJ. Antioxidant activity and protective effect of anthocyanin oligomers on $\mathrm{H}(2) \mathrm{O}(2)$-triggered $\mathrm{G} 2 / \mathrm{M}$ arrest in retinal cells. J Agric Food Chem. 2012;60:4282-8.

23. Lo YC, Lin YC, Huang YF, Hsieh CP, Wu CC, Chang IL, Chen $\mathrm{CL}$, Cheng $\mathrm{CH}_{\text {, }}$ Chen HY. Carnosol-induced ROS inhibits cell viability of human osteosarcoma by apoptosis and autophagy. Am J Chin Med. 2017;45:1761-72.

24. Costa RM, Filgueira FP, Tostes RC, Carvalho MH, Akamine EH, Lobato NS. $\mathrm{H}_{2} \mathrm{O}_{2}$ generated from mitochondrial electron transport chain in thoracic perivascular adipose tissue is crucial for modulation of vascular smooth muscle contraction. Vascul Pharmacol. 2016;84:28-37.

25. Li Z, Fang F, Xu F. Effects of different states of oxidative stress on fetal rat alveolar type II epithelial cells in vitro and ROSinduced changes in Wnt signaling pathway expression. Mol Med Rep. 2013;7:1528-32.
26. Sigaud S, Evelson P, Gonzalez-Flecha B. $\mathrm{H}_{2} \mathrm{O}_{2}$-induced proliferation of primary alveolar epithelial cells is mediated by MAP kinases. Antioxid Redox Signal. 2005;7:6-13.

27. Wang YX, Liu ML, Zhang B, Fu EQ, Li ZC. Fasudil alleviated hypoxiainduced pulmonary hypertension by stabilizing the expression of angiotensin-(1-7) in rats. Eur Rev Med Pharmacol Sci. 2016;20:3304-12.

28. Takano M, Nagahiro M, Yumoto R. Transport Mechanism of Nicotine in Primary Cultured Alveolar Epithelial Cells. J Pharm Sci. 2016;105:982-8.

29. Madden JA, Vadula MS, Kurup VP. Effects of hypoxia and other vasoactive agents on pulmonary and cerebral artery smooth muscle cells. Am J Physiol. 1992;263:L384-393.

30. Hauge A. Hypoxia and pulmonary vascular resistance. The relative effects of pulmonary arterial and alveolar PO2. Acta Physiol Scand. 1969;76:121-30.

31. Lourenco AP, Fontoura D, Henriques-Coelho T, Leite-Moreira AF. Current pathophysiological concepts and management of pulmonary hypertension. Int J Cardiol. 2012;155:350-61.

32. Song $T$, Zheng $Y M$, Wang $Y X$. Cross talk between mitochondrial reactive oxygen species and sarcoplasmic reticulum calcium in pulmonary arterial smooth muscle cells. Adv Exp Med Biol. 2017;967:289-98.

33. McCord JM, Fridovich I. Superoxide dismutase. An enzymic function for erythrocuprein (hemocuprein). J Biol Chem. 1969;244:6049-55.

34. Masri FA, Comhair SA, Dostanic-Larson I, Kaneko FT, Dweik RA, Arroliga AC, Erzurum SC. Deficiency of lung antioxidants in idiopathic pulmonary arterial hypertension. Clin Transl Sci. 2008;1:99-106.

35. Nozik-Grayck E, Woods C, Stearman RS, Venkataraman S, Ferguson BS, Swain K, Bowler RP, Geraci MW, Ihida-Stansbury K, Stenmark KR, et al. Histone deacetylation contributes to low extracellular superoxide dismutase expression in human idiopathic pulmonary arterial hypertension. Am J Physiol Lung Cell Mol Physiol. 2016;311:L124-134.

36. Hirobe T, Shibata T, Sato K. Human fibroblasts treated with hydrogen peroxide stimulate human melanoblast proliferation and melanocyte differentiation, but inhibit melanocyte proliferation in serum-free co-culture system. J Dermatol Sci. 2016;84:282-95.

37. ParkWH. Exogenous $\mathrm{H}_{2} \mathrm{O}_{2}$ induces growth inhibition and cell death of human pulmonary artery smooth muscle cells via glutathione depletion. Mol Med Rep. 2016;14:936-42.

38. Porter KM, Kang BY, Adesina SE, Murphy TC, Hart CM, Sutliff RL. Chronic hypoxia promotes pulmonary artery endothelial cell proliferation through $\mathrm{H}_{2} \mathrm{O}_{2}$-induced 5-lipoxygenase. PLoS ONE. 2014;9:e98532.

39. Jin $\mathrm{N}$, Rhoades RA. Activation of tyrosine kinases in $\mathrm{H}_{2} \mathrm{O}_{2}$-induced contraction in pulmonaryartery. Am J Physiol. 1997:272:H2686-2692.

\section{Publisher's Note}

Springer Nature remains neutral with regard to jurisdictional claims in published maps and institutional affiliations. 